\title{
Visualization of Legal Informatics
}

\author{
Friedrich LACHMAYER ${ }^{\mathrm{a}}$ and Vytautas ČYRAS $^{\mathrm{b}, 1}$ \\ a Vienna, Austria \\ ${ }^{\mathrm{b}}$ Vilnius University, Lithuania
}

\begin{abstract}
This paper explores the subject matter of legal informatics. The life-long work of the first author concerning the visualization and coding of statutes is generalized. Besides positive law and customary law, the emergence of machine law is a current topic of focus in the literature. In machine law, legal acts are posited by machines and not by humans (primarily in a situational context). The transformation of a legal act to a legal document can happen in two ways. First, it is a transformation of the legal act into explicit punctuation, for example, for announcement in the case of laws or for written execution in the case of judgments, and, second, as a trend towards electronic documents. Legal theory forms a meta-level to the law and similarly legal informatics forms a meta-level to legal information. Legal informatics in Austria is based on the work of Ota Weinberger, Ilmar Tammelo and Leo Reisinger and has been developed by Erich Schweighofer in the framework of the IRIS conferences. Legal informatics is distinguished from legal information, whereas legal logic and meta-theories appear on top of legal informatics. In terms of syntax, machine culture is characterized by formal notations. Notations of legal logic are just the beginning; the target is a technical notation, a basis for programming. Visualizations are in the middle. On the one hand, visualizations serve to understand people by breaking away from the textual; on the other hand, by emphasizing the formal they form a bridge to machines. Legal text can be translated directly into formal languages, but visualizations can facilitate this task as an intermediate methodological step. Hans-Georg Fill's metamodeling can be seen as a metameta-level.
\end{abstract}

Keywords. Machine law, legal act, legal document, legal logic, formalization, visualization

\section{Transition from Legal Act to Legal Document}

To date, the law has known two stages of development: customary law and positive law. A third stage of development is now emerging, namely machine law.

In law, a distinction must be made between the legal act (speech act) and a document (see Figure 1). The legal act of a law consists of the speech act of parliament. Usually, the announcement of the law will be added in a publication gazette, but the resolution of the law takes place in parliament and not in the publication organ. Similarly to a judgment, the announcement of the judgment will be constitutive and written copy can be added. Indeed, the judgment could also only be given in writing, i.e., without prior verbal announcement.

This is similar to legal documentation where the content of the legal act is shown in the document. In legal information, however, there is now a tendency for the speech act

\footnotetext{
${ }^{1}$ Corresponding author, Institute of Computer Science, Faculty of Mathematics and Informatics, Vilnius University, Didlaukio 47, Vilnius, Lithuania; E-mail: vytautas.cyras@mif.vu.lt.
} 
and document to merge: there is only one integrative act that consists of a legal act and an electronic document at the same time, if, for example, the legal act is already being set electronically by a machine.

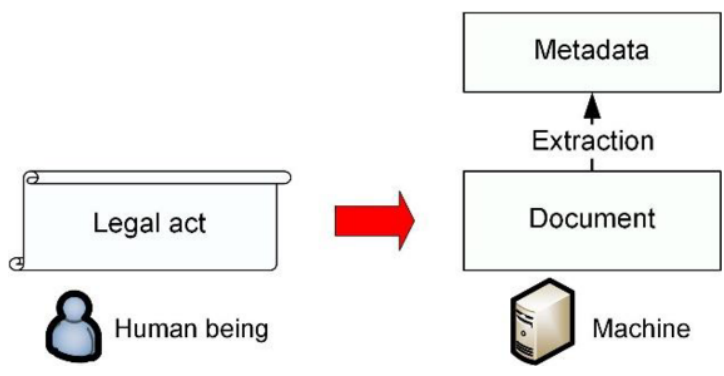

Figure 1. Transition from legal act to legal document.

So far, the law has been extensively posited. Situational norms also exist, such as traffic lights, but these have not been interpreted as their own norms, but rather as elements of the facts to which the norms were linked. Machine law will be posited by machines, especially in situational contexts. It is a question of legal or scientific interpretation whether these machines are interpreted as "persons" and the norm positing is interpreted as a "legal act". The 2001 IRIS conference was dedicated to this topic ("On the way to ePerson"). Nowadays the IRIS (International Legal Informatics Symposium; Internationales Rechtsinformatik Symposion) is held annually at the University of Salzburg; see https://iris-conferences.eu/.

The arrow in Figure 1 symbolizes the transition in two ways. On the one hand, it concerns the transformation of the legal act into explicit punctuation, for example, for announcement in the case of laws or for written execution in the case of judgments. On the other hand, there is now the trend towards electronic documents, for example, in RIS (das Rechtsinformationssystem des Bundes; the Legal Information System of the Republic of Austria, see https://www.ris.bka.gv.at).

Metadata can be extracted from these documents, providing the advantage of easier access to documents when searching. This means the full text search is no longer required. In addition, words not contained in the full text can be added. Additionally, the metadata can be extracted directly from the text. This is a topic in legal informatics.

The law itself can contain the type of metadata, for example, the legal principles in court decisions. These are generated by the court itself (see, for example, Felix Gantner's manuscript entitled Digital Transformation of the Law and also [1]).

\section{Legal Theory and Legal Informatics}

Legal theory is a meta-level to law, just as legal informatics is a meta-level to legal information (see the middle section of Figure 2, labeled Meta-level).

When legal informatics emerged, there were several variants of legal theory, such as traditional legal dogmatics, discourse theory, and, as before, theories of natural law. The scientific discourse at that time (at least in Austria) was also shaped by Hans Kelsen's Pure Theory of Law [2], the second edition of which was published in 1960. A peculiarity of the Pure Theory of Law lies in the clear line of thought and language, which is dedicated to the structural knowledge of the law and thus formed an analytical 
starting point for the subsequent legal informatics. Pure jurisprudence speaks about logic in law, but contains no formal expressions.

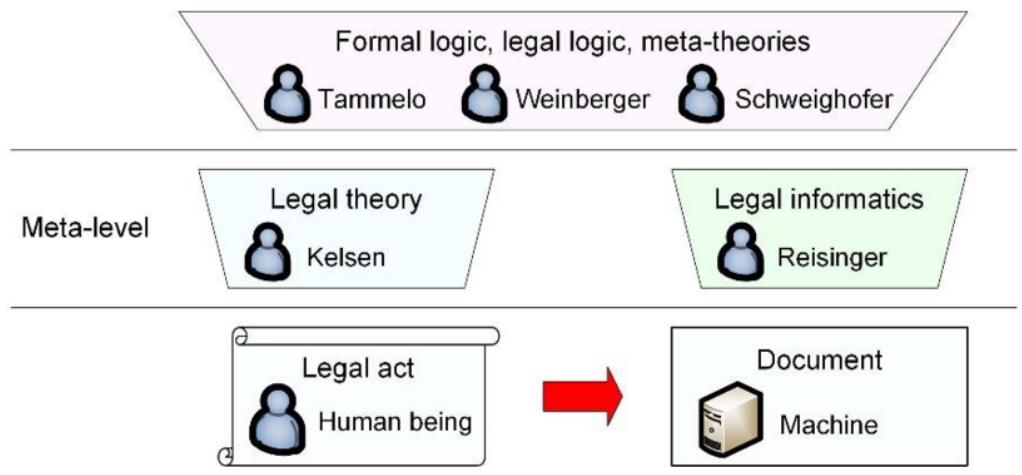

Figure 2. Legal theory and legal informatics on a meta-level.

Nevertheless, legal informatics must be distinguished from legal information. While legal information is usually implemented on a project basis, legal informatics is part of science and belongs to the meta-level of legal information.

Some researchers have viewed legal informatics as a "hyphenated science" because it has two subject areas, namely, law and information. This view of hyphenated science affected the selection of personnel because scientists with a double degree (such as Ota Weinberger, Herbert Fiedler, Leo Reisinger and Erich Schweighofer) gave qualified access.

At the beginning of legal information in the 1970s, there were two concepts for the projects: there was a demand market in which the IT producers had oriented themselves towards the peculiarities of the law and thus incorporated the results of legal theory into the documentation software. Over the course of time, however, this changed in the direction of a supply market: the general documentation software offered is so powerful that (almost) all problems of legal documentation can be solved with it and so it is no longer necessary to take into account (supposed) peculiarities of the law. Here, too, the truth will lie somewhere in the middle, as the vast majority of problems can be solved by general structures and the peculiarities of the law only make up a small but ultimately relevant area of software construction.

Leo Reisinger presented the state of development at that time in his book Rechtsinformatik, published in 1977 [3].

\section{Legal Logic}

For the development of legal informatics, legal logic, which was motivated in the early 1950s by Georg Henrik von Wright [4], constituted an important theoretical basis. Legal logic is clearly illustrated in Figure 2 and acts as a meta-theory.

The topic of legal informatics in German-speaking regions was initially treated theoretically, in particular by Herbert Fiedler [5], Fritjof Haft [6], Lothar Philipps [7], Jürgen Rödig [8] and Spiros Simitis [9].

The situation in Austria was as follows. From the point of view of the first author, the Czech legal philosopher and logician Ota Weinberger was the first to point out the avant-garde position of legal logic in Austria in 1968. The first edition of his book on 
legal logic (Rechtslogik) was published in 1970 [10]. Consequently, Weinberger became a professor in Graz. His student Alfred Schramm largely devoted himself to legal expert systems.

In 1973 the Estonian legal philosopher Ilmar Tammelo came from Australia to Austria and accepted a position as a professor in Salzburg after Rene Marcic (a representative of natural law). Tammelo was highly innovative and eager to experiment, as well as being in contact with many foreign scholars. The further development of formal notations was an interesting topic for him [11].

Leo Reisinger habilitated as a computer scientist (in Vienna) and a lawyer (in Graz). In the 1970s, he wrote several books on legal informatics. Concerning the logic of law, he adopted the model produced by Carlos E. Alchourrón and Eugenio Bulygin [12].

The first author of this paper has repeatedly taken part in Ilmar Tammelo's seminar in Salzburg. With this tradition in mind, the IRIS was founded in Salzburg in the 1990s together with Erich Schweighofer. The annual IRIS congresses have endeavored to offer a forum for both theory and practice in legal informatics, especially in the form of project culture. Because of Schweighofer's special merits, an extensive conference volume is published and given to participants at the beginning of each congress. With these volumes he creates a knowledge base for legal informatics that can be used in the following years (see e.g. the recent proceedings, IRIS 2021 [13]). In this way, Schweighofer has re-established the Austrian legal informatics community and provided further thematic impulses. Schweighofer has also written about the prospects for legal informatics and legal data science [14].

\section{Visualization}

Traditionally, law is textual. Jurists transform texts into texts. There are various kinds of texts: laws, contracts, claims, judgements, etc. Text transformations require abstracting, reasoning and other legal methods. Judgements, guidelines and their head notes are formulated in abstract legal terms. Abstracting and extracting are therefore needed and are performed by jurists and secretaries.

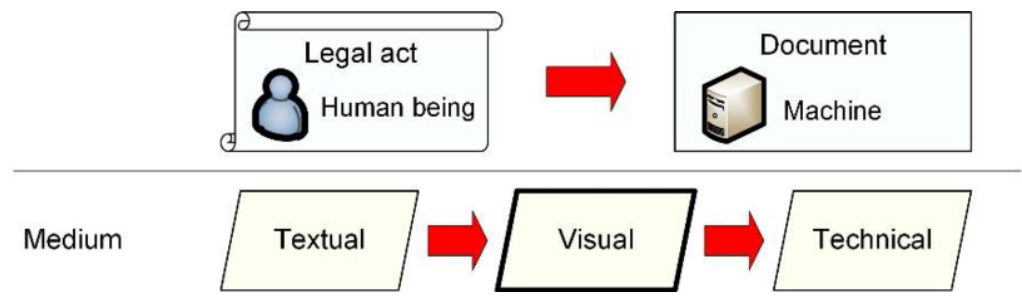

Figure 3. Legal visualization appears in the middle of the multi-arch bridge which leads from textual law to its enforcement by computer.

Hence, positive law, like traditional jurisprudence, is textual. In terms of syntax, machine culture is characterized by formal notations. The logical notations of legal logic are just the beginning. The target area is technical notations as the basis of programming.

Visualization can occupy a middle position (see Figure 3). On the one hand, visualizations can serve to better understand people by breaking away from the textual; on the other hand, by emphasizing the formal, they can represent a bridge to machines. 
It is possible that the texts are translated directly into formal language, but it can also be that methodological intermediate steps in the sense of visualizations facilitate this task (see Figure 4 and [15]). The authors have attempted to exhibit such intermediary possibilities in a series of articles (see $[15,16])$.

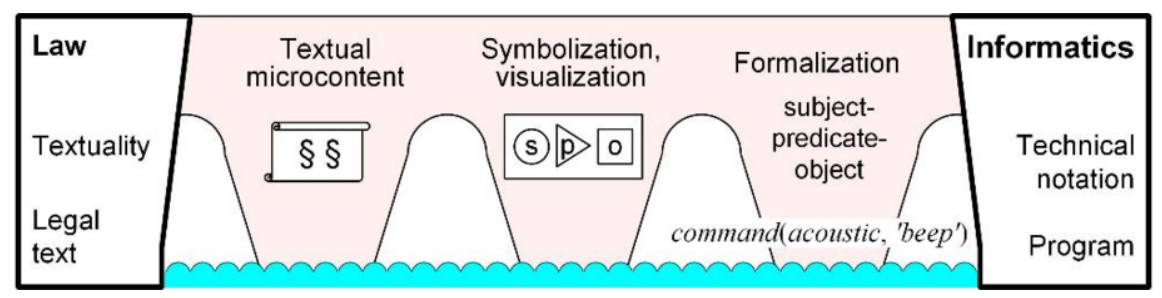

Figure 4. The multibridge metaphor: transformations lead from norm to its machine implementation [15].

The question of whether there is an independent legal logic or if this is simply an application of formal logic to the law is negated when the notation as a syntactic structure is in the foreground. It is entirely possible to develop a special normative notation, just as there is a specific chemical notation, for example, $\mathrm{H}_{2} \mathrm{O}$.

\subsection{Transformation from Legal Text to Computer Program}

The premise of this paper is that it seems unrealistic to proceed directly in one step from legal texts to their formalization (in the form of logic programming, e.g., Prolog). Intermediate steps are needed. In other words, we hold that a one-arch bridge is unrealistic and advocate a multi-arch bridge of some kind. Hence, an approach in legal informatics is proposed which is called Multi-phase Transformation.

There are many approaches to formalizations in the legal domain. Here, various formalisms, notations, logics and modelling techniques are used. As a one-bridge approach, Tammelo [11] addressed logic-based representation. He was successful in representing short legal texts in the prefix notation of binary operators. However, such formal notation was not easy to read. Sergot et al. [17] employed logic programming while representing the British Nationality Act as a logic program. Grabmair and Ashley [18] examined two transformations: First, the statute text is transformed into an Intermediate Norm Representation, and then to a rulebase.

Whilst the transformation is feasible in the case of a clear statement, difficulties arise with complex texts and a scalability problem is faced. Hence, the quality of transformation is acceptable for small texts only. However, the quantity (scalability) is not acceptable. Here the early attempts of artificial intelligence research on understanding natural language can be recalled. You can succeed in a world of toy blocks, but it would scarcely be possible to represent the meaning in the general case.

\subsection{Multi-arch Bridge Implies Multiphase Transformation}

The building of a bridge is continued with the observation that legal knowledge representation is needed as an intermediate step. The input/output chain is Legal text $\rightarrow$ Legal knowledge representation $\rightarrow$ Program. Next, Legal knowledge representation is decomposed into three intermediate stages: textual microcontent, symbolization/ visualization, and formalization (see Figure 5). 


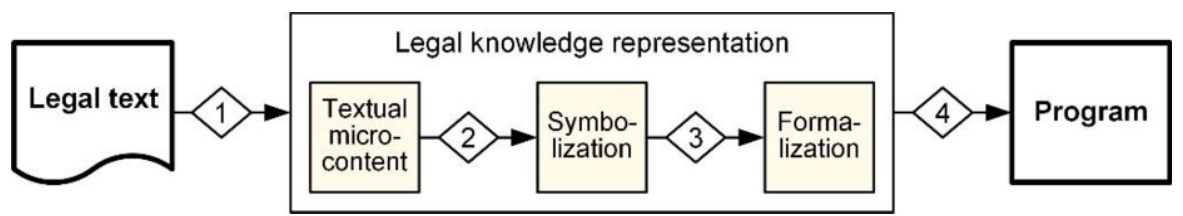

Figure 5. The Multiphase Transformation approach - a multibridge [16].

The four bridging steps in Figures 4 and 5 are represented by 'input $\rightarrow$ output' pairs:

Step 1. Microcontenting: legal text $\rightarrow$ textual microcontent

Step 2. Visualizing: textual microcontent $\rightarrow$ symbolization/visualization

Step 3. Formalizing: symbolization/visualization $\rightarrow$ formalization

Step 4. Implementing: formalization $\rightarrow$ program.

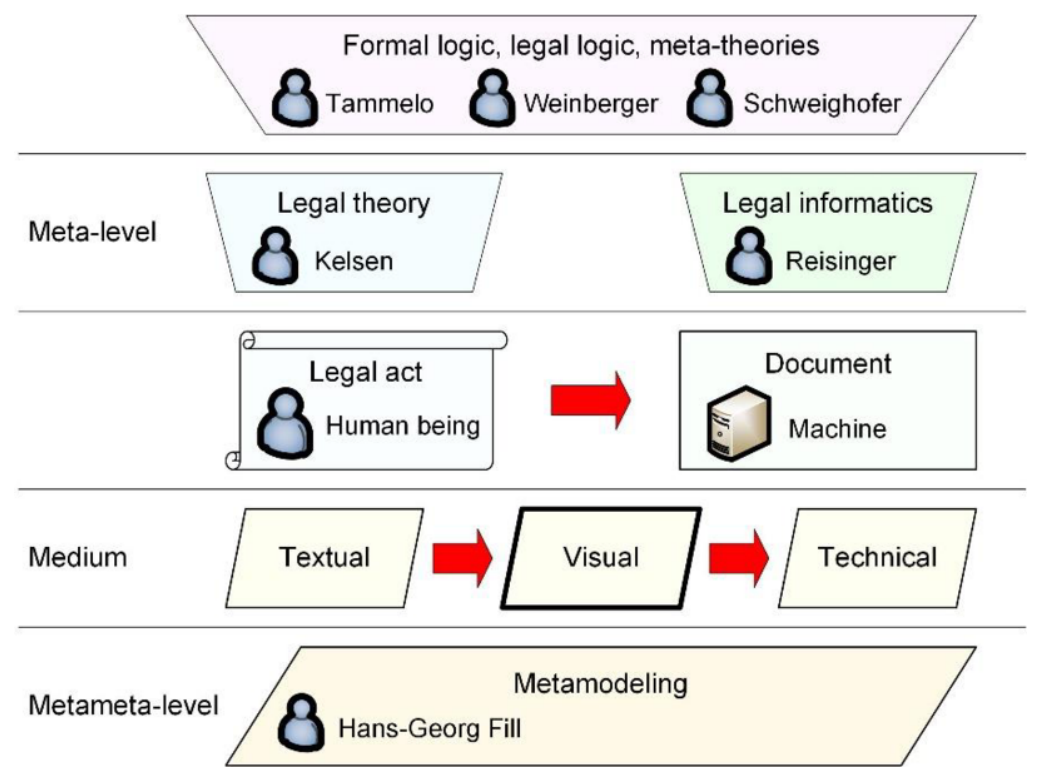

Figure 6. Summary of the discussed topics of legal informatics.

\section{Metamodeling}

The business informatics specialist Hans-Georg Fill has worked for years on conceptual modeling and visualization in the field of business informatics [19, 20, 21], and also on metamodeling for enterprise systems [22, 23]. We depict Fill's work on a metameta-level in our summarizing Figure 6, in which the relevant section is labeled Metamodeling. The semantics conveyed by a visual (i.e. the meaning of the representation) is addressed in [19]. Fill [19, p. 172] holds that "the goal of knowledge explication [...] is to explicate knowledge that resides in the heads and minds of people and express it by a visualisation". He lists four basic aims of visualizations: knowledge explication, knowledge transfer, knowledge creation, and knowledge application. Knowledge explication is a primary aim of legal visualization in our approach. 


\section{Evolution: Animals-Human Beings-Machines}

Consider the line of evolution from plants to animals to human beings to machines, as shown in Figure 6 [24]. In the proposed model, biological evolution leads to the development of human beings. The last step, the evolution from humans to machines, however, is a process of technological evolution in which humans produce machines. Moreover, humans strive to give human capabilities to their creatures, thus making machines artificially intelligent, a situation that is reminiscent of the ancient myth of Pygmalion and its modern variations.

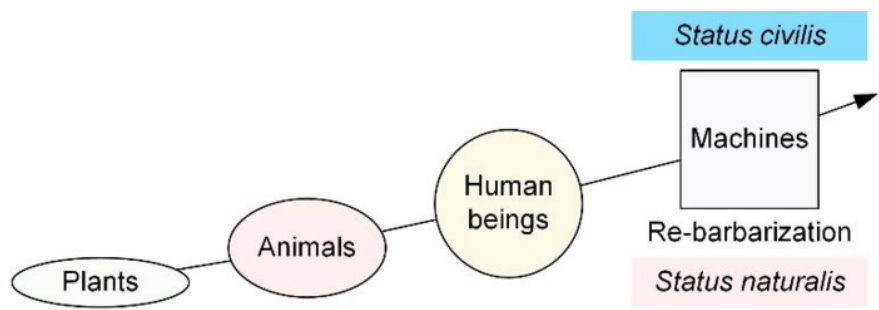

Figure 7. The line of evolution from plants to animals to human beings to machines [24].

One question associated with the evolutionary step from humans to machines is whether machines reside in status civilis or status naturalis. A relapse to status naturalis is a permanent temptation of modern culture, although re-barbarization is a kind of political atavism. Weapons are substitutes for the former raptors. We, however, maintain that machines have to be not monsters.

The theological problem of theodicy, ${ }^{2}$ which Leibniz addressed, namely, the place of evil in the Creation, arises again in the case of machines as human creations.

Legal informatics is not just a science that synthesizes between jurisprudence and technology, but it also gives the area of machines a human-like normativity, and it does the same in their role as actors on the human stage, which is transformed into a common stage.

We see the digital ubiquity of an organization, which is examined by Fill [23], as an issue in the evolutionary step to machines.

\section{Conclusion}

The topics explored within legal informatics are summarized in Figure 6. We hold the belief that the work in progress applies in particular to legal visualization, which acts as a bridge between people's textual understanding of the law and the formal, abstract notations of the machine world.

\footnotetext{
2 Theodicy means vindication of God. It is to answer the question of why a good God permits the manifestation of evil, thus resolving the issue of the problem of evil (see Wikipedia, https://en.wikipedia.org/wiki/Theodicy).
} 


\section{References}

[1] Gantner F.Theorie der juristischen Formulare. Schriften zur Rechtstheorie, Heft 252. Berlin: Duncker \& Humblot; 2010. 178 p.

[2] Kelsen H. Pure theory of law. 2nd ed. (trans: Knight M) (Reine Rechtslehre, 2. Auflage. Deuticke, Wien 1960). Berkeley: University of California Press; 1967. 368 p.

[3] Reisinger L. Rechtsinformatik. Berlin, New York: de Gruyter; 1977. 378 p.

[4] von Wright GH. Deontic logic. Mind 1951 Jan; 60(237):1-15. https://www.jstor.org/stable/2251395.

[5] Fiedler H, Haft F, Traunmüller R, editors. Expert systems in law - impacts on legal theory and computer law. Neue Methoden im Recht vol 4. Tübingen: Attempto; 1988.

[6] Haft F (2010) Das Normfall-Buch: IT-gestütztes Strukturdenken und Informationsmanagement. 4th ed. München: Normfall-GmbH; 2010.

[7] Philipps L. Endliche Rechtsbegriffe mit unendlichen Grenzen: Anthologia. Bern: Editions Weblaw; 2012. $232 \mathrm{p}$.

[8] Rödig J. Schriften zur juristischen Logik. Editors: Bund E, Schmiedel B, Thieler-Mevissen G. Heidelberg: Springer; 1980. 366 p.

[9] Simitis S, Hornung G, Indra Spiecker Döhmann I, editors. Datenschutzrecht: DSGVO mit BDSG. BadenBaden: Nomos; 2019. 1474 p.

[10] Weinberger O. Rechtslogik. 2nd ed. Berlin: Duncker \& Humblot; 1989. 432 p.

[11] Tammelo I. Modern logic in the service of law. Vienna: Springer; 1978. $196 \mathrm{p}$.

[12] Alchourrón CE, Bulygin E. Normative systems. LEP Library of Exact Philosophy 5. New York and Vienna: Springer-Verlag; 1971. 232 p.

[13] Schweighofer E, Kummer F, Saarenpää A, Eder S, Hanke P, editors. Cybergovernance: Proceedings of the 24th International Legal Informatics Symposium IRIS 2021, Feb 24-27. Bern: Editions Weblaw; 2021. 411 p. Jusletter IT, 25 February 2021. https://jusletter-it.weblaw.ch/issues/2021/25-Februar-2021.html.

[14] Schweighofer E. From information retrieval and artificial intelligence to legal data science. In: Schweighofer E, Galindo F, Cerbena C, editors. In: Proceedings MWAIL2015, ICAIL multilingual workshop on AI \& Law Research, 15th International Conference on Artificial Intelligence and Law (ICAIL 2015). books@ocg.at, vol 313. Vienna: OCG; 2015. p. 13-23. http://fedora.phaidra.univie.ac.at/fedora/get/o:399570/bdef:Content/get.

[15] Čyras V, Lachmayer F. Multisensory legal machines and legal act production. In: 25th IVR World Congress: Law Science and Technology; 2011 Aug 15-20. Series A: Methodology, logics, hermeneutics, linguistics, law and finance, paper No. 026/2012. Goethe University Frankfurt am Main; 2012. http://publikationen.ub.uni-frankfurt.de/files/24884/IVR_World_Congress_2011_No_026.pdf.

[16] Cyras V, Lachmayer F. Multiphase transformation in the legal text-to-program approach. In: Sturm F, Thomas P, Otto J, Mori H, editors. Liber amicorum Guido Tsuno. Vico Verlag, Frankfurt am Main; 2013. p. 57-70. Available at SSRN: https://ssrn.com/abstract=2632045.

[17] Sergot MJ, Sadri F, Kowalski RA, Kriwaczek F, Hammond P, Cory HT (1986) The British Nationality Act as a logic program. Communications of the ACM 1986; 29(5):370-386.

[18] Grabmair M, Ashley K. Towards modeling systematic interpretation of codified law. In: Moens M, Spyns P, editors. Legal knowledge and information systems. JURIX 2005: the eighteenth annual conference. Frontiers in artificial intelligence and applications 134. Amsterdam: IOS Press; 2005. p. 107-108.

[19] Fill HG. Visualisation for semantic information systems. Wiesbaden: Springer Gabler; 2009. 347 p.

[20] Fill HG. Transitions between syntax and semantics through visualization. In: Schweighofer E et al., editors. Zeichen und Zauber des Rechts. Bern: Editions Weblaw, p. 935-44; 2014.

[21] Pittl B, Fill HG. A visual modeling approach for the semantic web rule language. Semantic Web 2020; 11(2):361-89.

[22] Fill HG. Abstraction and transparency in meta modeling. In: Schweighofer E, Kummer F, Hötzendorfer W, editors. Transparency: Proceedings of the 17th International Legal Informatics Symposium IRIS 2014, books@ocg.at, vol 302. Vienna: OCG, p. 435-42; 2014. Jusletter IT 20 February 2014. doi: 10.38023/88d2121f-5631-433e-ab17-bace2ec98211.

[23] Fill HG. Enterprise modeling: from digital transformation to digital ubiquity. In: Ganzha M, Maciaszek L, Paprzycki M, editors. Proceedings of the 2020 Federated Conference on Computer Science and Information Systems. ACSIS vol 21, p. 1-4; 2020. doi: 10.15439/2020F001.

[24] Čyras V, Lachmayer F. Legal visualisation in the digital age: from textual law towards human digitalities. In: Hötzendorfer W, Tschohl C, Kummer F, editors. International trends in legal informatics: festschrift for Erich Schweighofer. Bern: Editions Weblaw; 2020, p. 61-76. 